\title{
CONSULTORIA EM PSICOLOGIA ESCOLAR/ EDUCACIONAL: Princípios teóricos e técnicos e contribuições de práticas sistematizadas
}

\author{
School/ educational psychology consultation: Theory and technical \\ principles and contributions of systematic practices
}

SILVA, M. B. (Org). (2009). Consultoria em Psicologia Escolar/Educacional: Princípios teóricos e técnicos e contribuições de práticas sistematizadas. Curitiba: Juruá.

\section{Ana Paula Fernandes Lopes Cançado ${ }^{[a]}$, Licene Maria Batista Garcia da Silva ${ }^{[a]}$, Rosana Angst ${ }^{[a]}$}

\begin{abstract}
${ }^{[a]}$ Alunas do curso de Psicologia da Pontifícia Universidade Católica do Paraná (PUCPR), Curitiba, PR - Brasil, e-mail: roangst@gmail.com
\end{abstract}

O livro organizado por Mariita Bertassoni da Silva e demais autores, intitulado Consultoria em Psicologia Escolar/Educacional: princípios teóricos e técnicos e contribuições de práticas sistematizadas propicia uma reflexão no que se refere à atuação do psicólogo no contexto educacional. Assim sendo, sua atuação compreende uma ampla gama de serviços abarcando todos os envolvidos no processo ensinoaprendizagem. O olhar do psicólogo como consultor escolar/educacional volta-se para o ato educativo com caráter preventivo e não curativo.

Nos nove capítulos que compõem o livro, os autores buscam explorar, debater e sugerir formas de intervenção do consultor escolar/educacional, visto que este é um tema que apresenta uma escassez de publicações bibliográficas. Sob diferentes perspectivas teórico/práticas, os autores vislumbram um objetivo comum: a implementação de ações interventivas que favoreçam o processo ensino-aprendizagem e o funcionamento da instituição como um todo.

Maria de Lourdes Bairão Sanchez, uma das primeiras supervisoras em Psicologia Escolar da Pontifícia Universidade Católica do Paraná (antiga UCP), no capítulo 1 intitulado "Um olhar distanciado" contextualiza o leitor, por meio de um relato de experiência do momento histórico, limites e potencialidades da atuação do psicólogo escolar, desde a década de 70 . 
No capítulo 2, apresentado por Mariita Bertassoni da Silva, o leitor é convidado a refletir sobre a prática do consultor escolar/educacional vivenciada enquanto modalidade de estágio curricular do curso de Psicologia de uma universidade particular. Este capítulo oferece um modelo de procedimentos instrumentais e teóricos e as habilidades desenvolvidas por meio desta prática.

Em "Consultoria escolar: um encontro entre psicologia escolar e educação" os autores realizam um trabalho de aprofundamento de aspectos técnicos, teóricos, instrumentais e práticos da consultoria, visto que é papel do consultor fortalecer e descobrir potencialidades na instituição para solidificar o trabalho em equipe.

No capítulo 4, intitulado "A consultoria em Psicologia Educacional como uma nova modalidade de emprego ao psicólogo escolar" elaborado por Fernanda Rafaela Cabral Bonato, diferencia a atuação do Psicólogo Escolar do Consultor Escolar/Educacional. Para embasar esta diferença de profissional, as autoras citam as leis que regem o trabalho de um consultor.

Em "Escola: Organização e consultoria sob a ótica sistêmica", capítulo 5, as autoras, salientam a importância de o consultor olhar a instituição como um todo, percebendo o seu público-alvo, missão, valores, metas e propostas. O consultor necessita ter um olhar amplo sobre a instituição e refletir sobre o melhor trabalho que cabe àquela organização.

"Família, escola e o consultor em Psicologia Escolar/Educacional na contemporaneidade" é o capitulo 6, de autoria de Tatiana de Souza Centurion e Vera Regina Miranda. As autoras fazem um retrocesso na história das famílias relatando suas evoluções e a maneira que foi se formando até os dias atuais. Diante dessas novas perspectivas familiares, as autoras salientam o papel do consultor como um facilitador na relação escola e família, vindo a melhorar o processo ensino-aprendizagem como um todo.

O capítulo 7, denominado "Promovendo a saúde do professor", elaborado por Cloves Amorim, salienta a importância de se voltar o olhar para a saúde do professor, sendo este um importante agente educativo, e que atualmente necessita lidar com diversas situações adversas no ambiente escolar.

"Considerações psicopedagógicas para compreender e intervir na instituição educacional" é o capítulo de autoria de Mari Angela Calderari Oliveira, que enfatiza a necessidade de um olhar sistêmico para a instituição escolar, e promove práticas que não envolvem apenas os aspectos cognitivos dos discentes, mas também os aspectos afetivos e emocionais de cada um.

Maria das Graças Fernandes de Souza e Patrícia Dietrich Schner relatam no capítulo 9, denominado "Consultoria em Psicologia Escolar/Educacional: relato de uma experiência como estudante e como profissional", a experiência de ambas como estagiárias nesta área de atuação, e posteriormente a atuação profissional. É enfatizada a importância da mudança de postura de estagiária para psicóloga, e como os estágios auxiliam para que essa transição ocorra de uma forma coerente e tranquila.

Por fim, acredita-se que o livro permite ao leitor reflexões no que concerne à formação, a prática e a inserção no mercado de trabalho do consultor escolar/educacional. Sem dúvida, a grande contribuição do livro é trazer ao leitor as possibilidades de atuação em consultoria escolar, trabalhando para a prevenção de dificuldades educacionais em todos os agentes educativos. Especialistas e estudantes da área da psicologia e da educação, ao lerem esta obra, irão instrumentalizar-se para trabalhar de forma eficaz no contexto escolar atual.

Recebido: 20/02/2009

Received: 02/20/2009

Aprovado: 24/04/2009

Approved: 04/24/2009

Revisado: 17/09/2009

Reviewed: 09/17/2009 